\title{
AMERICAN, SWISS, AUSTRALIAN, BRAZILIAN AND FRENCH YOUTH TALK ABOUT THEIR HOPES AND ASPIRATIONS FOR THE FUTURE
}

\author{
Nigel F. Bagnall ${ }^{5}$
}

\begin{abstract}
The prolongation of that period of life referred to as youth is well documented and accepted in the literature relating to youth. Dwyer and Wynn (2001) wrote of the new meaning of adulthood and the problem facing youth as they make a transition to a target zone that is constantly changing. The certainty of making a smooth transition to adulthood is no longer, if it ever were, assured. This study looks at a number of youth in what is often referred to as the transition phase to adulthood. They are in five different countries Brazil, France, Switzerland, Australia, and United States of America on four different continents. The individuals interviewed were generally between 18 - 30 years of age. They were asked a variety of questions relating to their prospects, hopes and aspirations for the future.
\end{abstract}

Keywords: Transition. Youth. Education. Belonging.

\section{Resumo}

O prolongamento do período da vida referido a juventude é bem documentado e aceito na literatura relativa aos jovens. Dwyer e Wynn (2001) escreveram sobre o novo significado da fase adulta e o problema enfrentado pelos jovens ao fazerem a transição para uma zona alvo que está em constante mudança. A certeza de uma transição suave para a fase adulta não é mais garantida, se é que um dia já o foi. Este estudo analisa um grupo de jovens pertencentes ao que é frequentemente referido como a fase de transição para a vida adulta. Os jovens provêm de cinco países, em quatro continentes diferentes: Brasil, França, Suíça, Austrália e Estados Unidos da América. Os indivíduos entrevistados tinham entre 18 e 30 anos de idade e responderam a uma variedade de perguntas relacionadas às suas perspectivas, esperanças e aspirações para o futuro.

Palavras-chave: Transição. Juventude. Educação. Pertencimento.

\footnotetext{
${ }^{5}$ The University of Sydney. Email: nigel.bagnall@sydney.edu.au
} 


\section{RevistAleph}

\section{Introduction}

This study on youth hopes for the future builds clearly on an earlier work of mine on youth and their perceptions of identity and belonging (Bagnall, 2015). In this work the focus of the qualitative study was to explore the boundaries of identity. In particular, the major focus was the identity of students in international schools in relation to their development of a global rather than a national sense of belonging. The students that took part in that study were all at international schools in six different locations. These students were considered to have one of three identities that were labeled national, global or uncertain. The primary focus of that study was to see what impact constant movement, more or less every three years, had on the students' and their sense of belonging. The group of students participating in this earlier study was from international schools in three different continents, Asia, Europe and South America. The schools were located in Rio de Janeiro, Paris, Berlin, London, Geneva (two schools), and Manila.

Amongst the questions asked of students in this study was where they thought they would be in 5 years time and in ten years time. It became clear from their responses that they were adaptable and saw the world as their destination rather than a particular country. They were generally not restricted by geographic or economic concerns and their future study location was dependent on a range of factors. These included where they had already lived, what they were hoping to study and like Zhanira who was at an international school in London, she wished to study further at ... a location that was beneficial for future career aspirations. (Bagnall, 2015, p. 91)

This new study on youth hopes for the future builds upon and in many ways is a continuation of the earlier study. The youth taking part are an older cohort than those in the identity study. They are predominantly aged between 18-30 years and live in France, Switzerland, Australia, United States of America and Brazil. This study accepts the notion of the prolongation of the transfer from youth to adulthood as being extended as a result of a number of key milestones being increasingly hard to achieve. These are often summarized as the completion of formal education, the achievement of financial independence and the departure from the family home and possible formation of an emotional bond with another person. As Miles (2000, p. 9) notes '... a key term in developing any adequate understanding of young people's lifestyles is that of 'transition', 


\section{RevistAleph}

the process by which young people somehow manage to reach adulthood. This study is concerned with the transition process as it projects into the future.

The cohort of youth participating in this study is quite different in a number of key areas. The 82 international school students were aged between 16 and 19 years of age and were all studying in international schools. Most of them were in their final year of school and would be moving for the first time to a destination that was not chosen or predicated upon predominantly by their parents work requirements. The choice of where to attend university was possibly the first time they had an independent decision to make and the reasons given for where this might be were varied and many. Raquel, a student of an international school in Rio de Janeiro was typical of a number of students when she stated:

[...] I wouldn't mind Europe. I've been to Paris and I've been to France. I really liked it. But I get the feeling that Italy would be like here. France is very good at engineering. Maybe even Australia would be very good, especially if I had a big place to live. I wasn't thinking so much of Asia.

This more recent study on youth hopes for the future looks at students in five countries on four different continents. Some are working, others are studying and yet others are trying to decide exactly what they would like to do.

\section{Rationale}

The increasingly interconnected world creates tension for concerns of new ways of seeing and being in the world. The surreal world of Facebook twitter Instagram and indeed all forms of social media provided on the Internet, has led to possible conformity within the physical world. There is an inevitable tension between the forces of homogenization and diversity. The visible signs of conformity are easily identifiable as the reckless youth in Prague hangs out in his or her Ksubi jeans, talking or texting on their I phone or equivalent and listening to music that is chosen from an eclectic collection of I tunes vast library. The virtually indistinguishable same look is emulated in New York, Delhi, Sydney and Rio. But are they all thinking in the same way about the future?

It is conceivable that this world that the youth of today are entering will be a place where borders are no longer drawn upon familiar national boundary lines but rather 


\section{RevistAleph}

global connections that reflect different levels of spatial and physical reality. A national border or any other geographic entity does certainly not restrict the movement of ideas and the creation of identity for youth. The creation of the European Community (EC) was heralded as a potentially unifying force for all the member countries. This conception of a European identity may have resonance in some countries within the EC. I would defy, however, anybody to tell a Greek person that his or her identity is destined to be similar to the youth of Germany or France or any other member country for that matter. Identity formation is a complex process and while it may be possible to see more similarities than differences between youth of Europe and South America, for example, the differences exist.

For an excellent coverage of the increasingly mobile aspect of youth with in their careers, David Cairns (2014) study on mobility and spatial reflexivity is a sound starting point. His book looks at the need for members of European nations in particular, to be aware that they are entering into a global job market. In his own words:

At the level of geo-politics, we also need to be aware that the ease with which young people move, including the enablement and inhibition of student movement, is affected by ideological battles, which take place at national governmental and European levels (Cairns, D. 2014, p. 41).

Cairns' study is predominantly dealing with European youth with much of his research undertaken in Portugal. The rich tradition of cultural and employment exchange within the European community with such programs as Erasmus, Leonardo da Vinci and the more recent Youth on the move initiative (YOTM) make the transition process for many students and youth within Europe looking for employment opportunities easier to access than many countries. The Brazilian government is also generous in terms of funding for students who wish to spend time abroad at some phase of their University education. By contrast, students in Australian institutions seeking to study abroad seem to have a more limited range of options open to them. This study looks at the hopes and aspirations of university students in Brazil, Australia, the United States of America, Switzerland and France. It attempts to show how their perceptions of the future may no longer be influenced by paradigms from the past.

Little research is done in Brazil, the sixth largest economy in the world. Research undertaken is generally focused on the inequalities that exist within the country and the 


\section{RevistAleph}

hopes and aspirations of the youth are seldom voiced. The same could be said for France although many sociology theorists come from that country. The work of Bourdieu on Social Reproduction theory has been well drawn upon for many years by sociologists and youth writers. Switzerland provides an oasis within Europe from the EC. It rests with in the study as a significant comparator. The youth within Switzerland are well placed to take advantage of their position within Europe. The final case study country in this paper, Australia, has continued to defy world economic trends but retains many of the problems of latter entry into the work force for youth.

Sometimes referred to as the 'new adulthood' with students staying at home longer, getting married latter and the emergence of diverse patterns of transition to adulthood, all these so called patterns of engagement with society are merged in this study. (Bagnall, $2005,2012,2015)$.

As Miles (2000: p. 9) notes '... a key term in developing any adequate understanding of young people's lifestyles is that of 'transition', the process by which young people somehow manage to reach adulthood. This study is concerned with the transition process as it projects into the future. Chopra and Gajjala (2011) in their edited text, Global Media, Culture and Identity: Theory, Cases, and Approaches are especially concerned with the future of media and looks predominantly at depictions of how identity, culture, media and globalization can be understood in our constantly changing world. Chopra's approach rests on three related propositions. In the present historical moment, global media are central to the production of cultural identity. Secondly that cultural identification is a key driver of logics and content of media flows and thirdly that expressions of cultural identity in media texts can be read as reflecting global awareness. (Chopra \& Gajjala, 2011, p.1).

Trudie Knijin suggests that there are three policy paradigms proposed by Schmid (2006) that are useful in viewing work transitions to adulthood. The first transitional labour market model is based on the assumption that post industrial labour markets working within a knowledge -based economy demand ... a flexible workforce, continuous innovation, and employees who have time for training, education, and care. Schmid, (2006) in Knijin, J. (2012, p. 23). The other two policy paradigms proposed by Schmid are the individual life-course model and the social investigation paradigm. Each of the three paradigms ... encapsulates the needs and risks of post-industrial welfare capitalism with four key words: new social risks, life-course, re-commodification and human capital (ibid, 


\section{RevistAleph}

p.25). The big question that Schmid asks is whether these social risks are categorized as resulting from the youth's own choice or are they more likely made from external circumstances outside their own control. In Schmid's own words ... do high dropout rates relate to individual choices of pupils or to suboptimal school systems? (ibid).

The key word in all three policy paradigms suggested by Schmid is human capital.

[...] although it has a distinct meaning in each one... in general it means that individual workers have to take responsibility for their employability, supported by either publically, collectively or individually paid education and training programmes (Knijin, 2012: p. 29).

The European Commission (EC) has also stressed that within Europe there has never been significant economic growth without population growth. Currently the average number of people born in Europe annually is lower than the preferred number.

\section{Methodology}

As noted earlier in this paper, there are several areas of academic endeavor that help frame a study such as this. These include but are not restricted to psychology, cultural studies, anthropology, sociology, and history. This study is a qualitative international and comparative study. Creswell and Plano Clarke (2007) note that qualitative data is comprised of open-ended information primarily gathered from participant interviews. The students studied in this research give answers in their own words. Additional data can also be gathered by observing the participants over a period of time in a variety of locations. The analysis of the qualitative data (words or text or images) usually takes place after aggregating the words or images into categories of information and presenting the diversity of ideas gathered during data collection.

The role of the researcher is more significant in international and comparative research as Landis et al. (2004, p. 155) point out. It is a question of the relativity of values and imposition of these upon the data. The self-positioning of the researcher is significant when interpreting multilingual discourse practices.

Giampapa \& Lamoureux, $(2011$, p. 127) note that ... Researcher identities, issues of postitionality (i.e. self-positioning, the positioning of others, and how we are positioned by others in the field), gender, language power, and agency are part of the process of 


\section{RevistAleph}

understanding and interpreting multilingual discourse practices. They refer in particular to an earlier study by Mullings (1999) who found that the researcher's knowledge is always partial because of their positionality. This refers to their unique mix of race, class gender, nationality, and other identifiers.

Writing in Markauskaite, Freebody, and Irwin's (2011) edited text on research methodology, I noted the need for the comparativist scholar to know his or her limitations as a researcher and to position themselves within the study. I noted four key points that were worth considering:

1 Know your own culture

2 Know as much as you can about the culture or cultures that you are studying (language, customs, history, politics, sports, etc.)

3 Constantly challenge assumptions (eg: French people are arrogant, Germans are highly organized, Australians are easy-going, Laos people are gentle).

4 Assess your strengths and weaknesses and play to your strengths (Markauskaite, Freebody, \& Irwin, 2011, p.204).

\section{Brazil}

Why study students from Rio de Janeiro? There are several reasons why the Brazil study is important in this paper. As noted earlier, Brazil is a newly developing nation whose economy is currently ranked 8th in the world. There are many discrepancies that typify the range of distribution of this wealth and none more so than within the education system. Paulo Freire, arguably one of Brazils most cited writers talked of the way society becomes standardized. Writing in the 1970s he stated that ... Men begin thinking and acting according to the prescriptions they receive daily from the communications media rather than in response to their dialectical relationships with the world. (Freire, 1970, p. 80)

Nearly fifty years on since this prophetic statement, the Brazilian study will attempt to make the position clear of where the youth of Brazil envision their future to be. Will they be limited by what Freire called the oppressive reality imposed by the power elite? His last sentence in the book sums up his position. If we have faith in men, we cannot be content with saying that they are human persons while doing nothing concrete to enable them to exist as such. (Ibid p. 83.) 


\section{RevistAleph}

The author has been to Brazil several times. For most of 2011 he was living in Brazil. He has visited a number of different parts of Brazil during these visits. The University chosen for the study represents one of the most powerful cities in Brazil. Speaking reasonable Portuguese the author feels confident that he has gained a range of voices from the students attending the University that agreed to take part in this study. The University chosen within Rio de Janeiro is a large university with a diverse student population.

\section{France}

One of the key countries in Europe, the French study helps give credence to a European youth voice. There is no single voice that typifies any country or continent, however, taking the hopes and aspirations of French youth will enable a picture to emerge of just how the French youth are traveling. John Ardagh writing in the1980s said that once the stagnant economy had been turned into one of the worlds most dynamic and successful ... Prosperity soared, bringing with it changes in life-styles, and throwing up some strange conflicts between rooted French habits and new modes. (Ardagh, J. 1982: 13). How do the French of today view the world? The French have always considered them selves different to the rest of the world. The subsidies they paid their farmers to produce off small uneconomic farms became the laughing stock of Europe, certainly those that were members of the European Community.

Michael Crozier an esteemed sociologist in the1960s had been one of those ... who dared hope that economic change might help to unblock society: yet in 1979 he was writing of France as still a stratified society which, very largely, has progressed negatively towards a greater rigidity - a society whose citizens are passionately attached to the distinctions and privileges which separate them.

\section{Australia}

Why Sydney and Melbourne? One of the most immediate impacts of globalization felt by Australian society results from the creation of a global marketplace. The change in location of manufacturing to the countries with the cheapest labour supply has meant 


\section{RevistAleph}

that many traditional entry-level jobs have disappeared. (This is also true for France and Brazil). This has had major ramifications for those entering the workforce for the first time, predominantly youth. One of the influences on youth intending to leave school has been a higher apparent retention rate. It has also meant that there are a greater number of students attending higher education institutions. The sorting and sifting process is being taken higher up the school/formal education chain. The so-called transition of higher education from an elite to a mass phenomenon has had a number of implications. It has led to an inflation of qualifications at the tertiary level as more students are participating in higher education. Gary Becker (2002) talks about human capital as the major form of capital in modern economies. Rather than economic indicators such as staff-student ratios and progression rates, he feels that economic successes of individuals, and indeed, countries' economies are contingent on how effectively people invest in themselves. He noted that while technology may be the driver of a modern economy, human capital is the fuel. Australian students are no longer competing solely against Australian applicants for jobs. Teaching positions, especially at the University level, are fiercely contested by a globally mobile work force.

\section{Research Questions}

The manner that interviews were conducted varied between countries. Usually the author was doing one-on-one interviews that were audio recorded and transcripts made which were then sent back to the participants and altered where necessary for accuracy. The interviews in Rio de Janeiro were all video recorded and transcriptions made from the video recordings.

The questions were semi structured and students were prompted where necessary if they did not understand the question or needed clarification on some aspect of the question. Students were able to withdraw from the interviews at any time and had all volunteered to take part in the study. Most students had not been shown the questions before hand and with the exception of the Brazilian students, the interviews were done one-on one. The Brazilian students were predominantly postgraduate students at a large University in Rio de Janeiro.

The following list of questions was asked of all participants. 


\section{RevistAleph}

1. Tell me a little about yourself? Where you are from and what you are currently doing in your life?

2. If you could change any three things in the world, what would they be? (Imagine that you are the most powerful person in the world and could change anything).

3. Where would you like to be in 5 years time and 10 years time?

4. When you think of the future of the world today, do you think positively or negatively about it?

5. When I asked you if you would mind taking part in this study on youth and the future, is there anything that we have not talked about that you thought we would cover?

\section{What the Brazilian youth had to say}

The youth taking part in the Brazilian study were all students or teachers within the same University ${ }^{6}$. Their interviews were video recorded and their responses were transcribed and thematically grouped. As (Creswell \& Plano Clarke, 2007, p. 26) note ... The analysis of the qualitative data (words or texts or images) typically follows the path of aggregating the words or images into categories of information and presenting the diversity of ideas gathered during data collection. Most of the participants interviewed in Brazil were interviewed in their native Brazilian Portuguese but some were confident enough to be interviewed in English.

There was little doubt that they were concerned with global events and their responses reflected this concern. The initial sentiment echoed in many of the interviews was that the world was in a dark place but that there was always a way forward. Isabella, the first student to be interviewed in Brazil, identified two things only in her response to the first question, which asked if you could change three things in the world, what would they be. The first was the violence in the world, as well as in Brazil. The second was a personal concern in wanting the $\mathrm{SAT}^{7}$ tests she was preparing for to be cancelled. She also noted that she wished she knew how to speak English better. In five years time she hoped

\footnotetext{
6 Doing research in comparative education is not always straightforward. The interviews in Brazil were undertaken in November 2015. The day after the first round of interviews was undertaken, the University in which the students were located was indefinitely closed by the Vice Chancellor, as there was a major fiscal crisis. The University was unable to pay its security staff and the attendants who work on the lifts. While the opportunity to do follow up interviews was lost, the initial interviews had been video recorded and the transcripts were able to provide a significant range of responses.

7 Scholastic Attainment Test. Isabella was hoping to do further study on finishing her undergraduate degree in Brazil and needed to sit these externally moderated exams to qualify.
} 


\section{RevistAleph}

to have finished her Bachelors degree and her Masters degree. In ten years time she would like to be finishing her PhD. Her overall feeling about the future was positive but she felt that the big things facing the world in the future were "... a lack of belonging for people and a lack of tolerance".

Adrianna felt that the three major problems facing the world were lack of tolerance lack of food and the fact that so many people went hungry daily and the behavior of people. In five years time she hoped to be married with a family and have finished her Bachelors and be well on the way to finishing her Masters degree. She was leaving Brazil in a few months time to live with her Aunty in Noosa, Australia for a year and was excited about that and the possibilities it would offer her. She felt that the big problems facing the world were all influenced by the way people think about the world and their place in it. She felt that if people could change their perspective and not be so selfish, the world would be a far better place. In other words the troubles of the world would not necessarily be problems if you didn't see them as being problems.

Sylvie believed that the world lacks values and would benefit from a lot more guidance for people and that's why it's the way that it is. Inequality was another problem caused by a large number of people having a lot and many people having nothing. Thirdly there are many problems if people don't consider religion. The lack of God in people's lives is a problem. In five years time she wants to have finished her schooling. She wants to have finished her concourse and have found a position in the air force or with the police. She wouldn't mind if she became a teacher. She wants to be married and happy in ten years time. She thinks if she were in the military she would be pretty content as she studies judo and they have lots of sport for people in their spare time in the military. She feels that society lacks love and a belief in God. Once you get cold about your feelings, that's when the trouble starts. The family structure is very important for society today. If you don't have a strong structure of family then you don't have a strong, resilient society.

Adriane was the oldest candidate interviewed. She was 37 years old and was married with two children. She had graduated with a Bachelor degree last year and was currently enrolled in a Masters degree. She wished to change the poverty in the world and felt that while there was lots of wealth in the world, it was not equally distributed.

Secondly she felt like she wished she could change the relationship that places a barrier between the ability to have children and to still be able to work. She felt like she 


\section{RevistAleph}

was missing out on knowing how her own children worked. The third problem facing the world was selfishness in the world. This was an impossible thing to change as it is related to human nature. In five years time she wanted to either have finished her doctorate or be in the process of finishing it. She also wanted to buy a new house (she laughed) and went on to list some other things she needed.

In ten years time she wished to have passed a public job concourse and to see her own children grow up and follow them in their successes. She reflected that selfishness is the biggest problem facing the world. We think that our problem is great and that everybody else's is small. She said that when she was 18 she had no thoughts about children and their needs but since studying pedagogy and taking part in talks about exclusion it makes her think a lot about children and how they might miss out with working mothers.

Taibaniz was a 23 -year-old student who felt strongly that politics ${ }^{8}$ was the major core problem. She felt that "... generally there was a lack of participation by Brazilian people. Police were also problematic however the politics and the leadership of the politicians in power were not doing enough to change adult education, in particular, which could help make a difference in the creation of a more equal society." In five years time she will either be finishing the Masters degree and going to work or starting to work on her Doctorate. She believes that if she was working in politics or public policy, she has ideas that would help to change the political mood of the University. She feels strongly that there is a lack of tolerance of difference and to differences between people within society. "Everybody is convinced that his or her own views are right".

Taina is 21 years of age and agrees with Taibaniz that the major problems in the world are caused by politics. Inequitable access for all to education and health services also creates problems. In five years time she thinks she will be in a smaller city and working with young children. Hopefully she will have completed her Masters degree by then. In ten years time she hopes to be married. "The biggest problem of all is lack of compassion for others".

Roberto believes that people need to be less selfish. They should not be obsessed with power and need to be able to put themselves in the place of others. She feels that

\footnotetext{
${ }^{8}$ Dilma, the Brazilian President had not been impeached at the time of this interview. Brazil had not yet hosted the Olympics but had successfully hosted the World Cup football competition in June-July of 2014.
} 


\section{RevistAleph}

people need to be passionate and show compassion towards others. She is very open to the future because she doesn't like to plan things a lot. In five years time she hopes to have established herself somehow in her career and be in a position to help her family in a major way. She notes that she has an Aunty in the United States and she would like to go there and spend some time with her. She wants to find a husband now and believes that that is a real tough job.

The biggest problem she states as for Adriane and Taibanz is that "... people are selfish and do not think of the needs of others. They think only of themselves and their hopes and needs. That's the real problem."

Marcel felt strongly that access to education is a major issue. Because people who have money can go to a private school or later Medical school or University, they have an advantage. Those in a school like his in Nova Iguaçu ${ }^{9}$ have generally no chance to go to a Doctoral program at a University or study to become a professional person such as a Doctor or Lawyer.

Secondly he would change people's views of the 'other' because felt that people living in the street didn't get much sympathy. "It's not a lack of love. People love to be loved. People get disappointed about gay love and it stops people from doing stuff'.

He believed that it was a fascination with money. ${ }^{10}$

In ten years time he would like to finish studying psychology and continue on to do a Doctorate. "... Not in psychology but in education."

He felt that the most important thing is for people to have empathy for each other. He said, "... it's not a lack of love that challenges the world it's just that people need to be loved."

Gabriella was convinced that the biggest problems facing the world were "... the inequality of access to education for all, respect for life of others, lack of love for others,

\footnotetext{
${ }^{9}$ Nova Iguaçu is an outer suburb of Rio de Janeiro that the Professor I was working with in Brazil had used as a case study for another project. I was involved in this study. It was an ongoing project that was looking at a range of issues affecting student access to further education. The Associate Principal of the school was aware that students could not easily transition to further education on completion of study at her High School. I was personally involved in this project over a 5 -year period and it was one of the highlights of my study in 2015 to see students who had been involved in the earlier project having made the journey to higher education. Marcel was one of those students.

10 I asked Marcel at this point of the interview if he felt that students had been asking each other the questions, whether the responses would have been different. He thought that if you had this conversation with students "... it would be a lot looser in terms of responses but ultimately the same things would be said".
} 


\section{RevistAleph}

the conflicts of politics and religious fanaticism." In five years time she hoped to have gained her Masters degree and passed her public concourse for her future work. The biggest problem facing the world was a "... lack of love for others and a lack of respect for the lives of others."

Juliana was very clear about the problems facing the world at present. The first thing she felt was the "... nature of human relationships. Because the ego-centric parts and selfish behavior of human nature lead people to do things by personal interest and what you are going to gain by the exchange". The second thing was the relationship between man and nature ${ }^{11}$. The third problem was inequality between people and indeed countries.

In five years time she hopes to have her Masters degree and to be in a position where she can help to support her own family. She wants to be by herself. In ten years time she will be working towards and finishing her Doctoral degree “... and traveling somehow through other countries and cultures".

She stated that while she is in schools observing other teachers teaching they often ask her what they think the problem with education is and what can be done to improve it? She says that she doesn't really know what to say to them to answer this question and that the teachers always "... give up on the students, give up on the class and never find out how to get through to them."

She believes that there may not be anything wrong but when the students are asked who their favourite teacher is they say Mr or Ms X and when they say why that teacher they say ... because the teacher cares about us. He or she likes them.

Luís Paulo is a teacher in a primary school in Rio de Janeiro. He thinks that he will have to change himself before changing the world as the first problem. "I think I have to change myself, my position and my perspective". Secondly he thinks that he will have to change his location, his job and his University. The biggest problem he sees in Brazil is the state of politics. The corruption within government is not good for him.

He doesn't have any brothers or sisters and sees himself in 5 years time finishing his PhD with his Professor. Probably he will get himself a car and a house. "I think I will have need of a good job".

\footnotetext{
${ }^{11}$ By this she meant the way that mankind treated the environment with a lack of respect.
} 


\section{RevistAleph}

In 10 years time he is not sure but "...maybe I will have a job at a University and I will have my group and my assistants and students, they can organize my life. And I will be happy".

He sees that "... maybe it's a question about economics, government and the way money is organized ... its not very well organized ... there is too much inequality".

The final formal recorded interview was with Suzianne, a doctoral student. She was 34 years old and married. When answering what three things that needed to be changed she started with education. "Not only assessment but the way that you do it. For example here in Brazil we are thinking about the system. I think it is important to be more student focused. The student is at the centre."

"I think the second one is inequality. When we don't have a good education system it's the same as inequality."

"And I think the third one is intolerance. If we don't have good education we don't have equality, we don't have tolerance.

In five years time she hopes to have completed her PhD and have a job. She added that she wanted to be a mother and have children. "This is one plan ... the truth is I

normally do this kind of plan for one year. But not now, (for family), I need to get a job and after I do it (get pregnant). She stated that last year she was in England. "I did not have this plan."

She noted that 10 years from now was a long way off. "Ten years it's really far from here now but I want to continue to be married. I want to have more children cause I want to have a large family like three children - I like children."

She added that there were many reasons why the world was the way it is. She was generally positive about the future of the world but felt that many things needed to change and education was a big player in helping make changes that were necessary.

In her own words she stated "... If you stop and take a look you can see that education is one factor, a strong thing. There is a political fault; there is a tolerance, not one thing. Many things and different things."

\section{What the French youth had to say.}

The first three French interviews were carried out in August 2016. Two were 


\section{RevistAleph}

undertaken in French and one was taken in English. Jennifer, not her real name, had just turned thirty. She spoke very good English and the conversation went back and forth in a combination of French and English. She was born in Saint Lazare where her father worked for Aérospatiale (now known as Airbus). He and the whole family were moved to Melbourne Australia for three years and on returning to France he was placed in Toulouse. This is what she had to say.

So I am Jennifer, I'm from Toulouse. I studied for A-levels for 4 years in Political Sciences. During this period I had a lot of opportunity to do a lot of training. I decided to go for communication training, but after doing this I realized it was not for me. So I decided to go for business school. ... I decided to go for a financial career ... and after my final year decided to go for Deloitte's where I have been for 6 years and two months ago I decided to move to a new company where I am also involved in financial planning but in a smaller firm.

When asked if she would consider moving out of France in the future to work she said: ...Yes well I would like to but I am already in a senior position and moving me would mean that I am quite expensive to employ. I could have imagined going abroad but ... I guess that in the USA it is quite hard without a visa. In the UK it is quite hard with Brexit and it's not so easy now.

The three major issues facing the world, and France in particular, elicited the following response. Well in France one of the major issues is terrorist attacks and the security issue, while making sure we are still in the democratic system. So what is the balance between enough security and enough freedom? Big brother \{is\} watching you.

Interviewer: France does seem to have been badly affected.

Jennifer: I guess it is something for looking at especially at my age. In finance it has a lot of economic influence on my world, especially of work. Especially well with the terrorist attacks. I heard that the tourists dropped by $40 \%$, so it is going to affect the economy any way.

Second concern. How are we going to find jobs? So that is a big issue. Third concern. Another big issue is the problem of the environment. We have heard about these illnesses where you are eating meat, mad cow disease. So all our industries we are polluting. We do not know what is going to happen to our industry.

Another thing, is how are going to cope with inequality in the world, because in France we are now, quite obviously good. We have rights, but what is going to go on with other countries - where they have no rights? How are we going to go forward and not backwards? There are many global problems, those are the key ones. Is the United Nations an organization that is still able to face the problems that we have? I guess 


\section{RevistAleph}

that we are a bit in turmoil, and no one is stepping up and nothing is happening.

Interviewer: Where do you think you will be in 5 years time and 10 years time?

Jennifer: Probably in 5 years time I will be in Paris. Now to tell you 10 years it's possible in Paris still but in another job in another company. I would like to be in a developing country and help give them direction. But that is rather imaginative. Once you begin a work \{job\} and it's going well for you, you want to stay with that because you are afraid of the future.

When asked what if there was anything that we had not talked about that she thought we would cover she had two further responses. She wondered if there was anything that she could have been told that would have made things easier for her transition to work. She felt that ...new students want to have fun in their life and not only working. New students are not eaten by the connection between what they want to do and wanting to have a job. She went on to say that she felt every five years or so you needed to build on your CV and make changes. The next generation ... is not so upset by the hierarchy.

Suzie was from Carpentras in the south of France and was 19 when interviewed. She had a classic French education undertaking the Baccalaureate in scientific studies. On completion of her Bac she left home for further studies. She was young (16 years old) when she completed her Bac and shortly after this she left home to undertake preparatory study for engineering in Marseille. She found it difficult to leave her parents who she was close to and felt ...very alone during these prep years. It was difficult for me to adapt to a new town, although I always lived in a village. And knowing no one.

After completing the competitive entrance exam she went to Paris to a Grand École to start her three-year course as an engineer, specializing in mechanical engineering. She has completed her engineering degree and was about to go and work as an intern for six months in Switzerland with Richemont, a famous watchmaking group.

Then I will return to Paris and I would like to spend a time in Canada to get a double degree. ... I know it is unthinkable as an engineer not travelling. Now if you don't open to the world, learning new languages, seeing how others are working in different countries you are sure to close yourself to some interesting opportunities for your career.

In response to the question of where she wanted to be in five and ten years time she replied: 


\section{RevistAleph}

Okay so for the next five years I would like to travel a lot more. The thing is I would like to travel with my boyfriend but it is not easy to travel together as we do not work in the same area. Me I would like to travel and be with him but I do not want to get to 30 and then think I have missed out on having children.

I think that more than ever, very early, we have to choose between career and family. I am 19 years and I have already thought a lot about it. As an engineer I will have to spend 10 hours a day working, plus the time for commuting. And opportunities are centralized in Paris. But I don't want to raise my children there, no way! So work takes more and more a huge part of our life. For example, I have one friend and one cousin who made a burn out although they were less than twenty years old!

The third French interview was with Pierre who had just finished school and was 18 years old. He lives at present in Tournefeuille ${ }^{12}$ with his parents. He hopes to work in design in the future and possibly management in the field of product distribution. He had spent five years at school in Italy and is bilingual in Italian and French. His family had moved back to France from Italy in order for him to complete his Bac Generale. He noted that Universities in France take you on the specialism that you choose.

The most significant problems currently facing the world for Pierre were ... the problem of terrorism because there are people that murder and have no sense of right or wrong. Other problems are sickness, globally the break down of family. Terrorism since November (2015) has been hectic. A real problem in the whole world, not just France. They wish to change the mode or style of life. Energy is also a problem, if not sorted the world will have some major problems in the future. Use the car less ... everybody needs to do this, certain countries, for example in Africa, it's not possible to ask them. But the countries that are developed, Europe, the United States etc.... they take the energy.

Luke felt that for the next five years he would be studying and the next five he would be working in the area of design. He would definitely be living independent of his parents. I don't think I will be getting married. That does not interest me at all at the moment.

The media heavily influenced his position on the way the future looked. If we see, look at, the media, it is not great. But things look bad ... Yes for the media; I think the most interesting things are negative. They speak of the games but not the politics. The media manipulates the results.

\footnotetext{
${ }^{12}$ Tournefeuille is an outer suburb of Toulouse.
} 


\section{RevistAleph}

\section{What the Australian youth had to say?}

The first Australian to contribute to the study was Roger. He grew up in Melbourne and had attended the same private school from year 3 to 12. At the time of the interview, he was in the process of finishing off a commerce degree. He had just turned 20 and was living and studying at a University in Melbourne. He had travelled a little between New Zealand and Australia but never lived out of Melbourne for any length of time. When asked what were the three biggest problems facing the world he stated that ... well I came up with three things and they are sort of interlinked and they are big picture things. The first is the population problem, then resources running out and finally inequality. And the three are interlinked. I think the fact that there are massive populations in countries that are not sustainable, and the resources are finite and inequality from people who want to move out of poverty and also unbalanced distribution of resources globally.

Well I think the question of the sustainability of resources and how you are going to do that. [...] We need to find a different way to live sustainably. I think that there are some short-term issues that we need to deal with as when they become long term we have some problems.

When asked where he felt he would like to be in 5 years and 10 years time he had this to say. I've been thinking about it a lot but not coming up with many answers. It depends whether I want to start work or start another degree. It was easier before when you didn't have to worry about fees and just started another one. But fishing around you do have to worry about it. Very much reflected by those doing Arts. They start realizing at the beginning of the $3^{\text {rd }}$ year that they have nothing to go to work wise

Interviewer: So what about in 10 years time?

Roger: Yes how old will I be then, 30 years. Yes I had better have my shit together by then. But I think like the same, I want $t$ be more established in 5 years. Work, doing lots of music and sports and stuff.

Interviewer: Ok, so when you think about the future, do you think about it in a positive way? Do you feel hesitant?

Roger: I think that at the moment I am pretty negative. A bit, yes I feel quite daunted about not having an idea about what's the future looking like! I see a lot of people who have an idea about what they want to do. It's always what are you going to do when you grow up and then it 


\section{RevistAleph}

becomes what are you going to do after your exams and then it becomes especially what are you going to do next year ... then its all the same stuff.

\section{Discussion of results}

There is little to indicate that students were apprehensive about their future in Brazil. While events may not always indicate the future as a safe and assured pathway in any country, these Brazilian students seemed to be readily embracing the future. They were, it is clear, all fairly well placed to deal with life as they had managed to get to University and study. The system of education in Brazil is difficult to negotiate for many and as Marcel noted it was unusual for people from his school to get to University. He, and several others from his school, had been able to make it to tertiary study. This was a pathway that was more easily negotiated by those who had greater economic ability to help them into the private or public University system.

Perhaps the most consistent theme raised through the responses of the Brazilian youth, was the need for a greater amount of tolerance, understanding and love between people.

The manner in which the interviews were undertaken would have influenced some of the participant's comments. By hearing the response of others, rather than being interviewed individually, students may have adapted or adopted what they had to say. The idea of a focus group situation, such as this one, was to encourage debate rather than influence responses.

\section{Conclusion}

The students responding in this section of the study seemed unsure about how the future would unravel for them, but were comfortable with the degree of uncertainty they saw ahead of them. The concern for all of society, not just the sector that they occupied, was obvious. As Juliana noted above when asked about one of the three things she felt needed changing, the first thing was:

[...] the nature of human relationships. Because the ego-centric parts and selfish behavior of human nature lead people to do things by personal interest and what you are going to gain by the exchange. 


\section{RevistAleph}

Kitty te Riele (in Bagnall, 2005, 48) wrote of the transition process from youth to adulthood as ... inevitably affected by the social, cultural, economic and political context of the society in which a young person lives. She argues that with the transition of contemporary developed nations societies towards a knowledge-based economy, that the ...timing of transition to employment and independent adulthood thus has been postponed. (ibid).

The five nations involved in this study are all developed nations on four different continents. The interviews taken in this study across a range of youth from 18- 30 years old, some working and many in education at the time that they were interviewed, maintained a positive outlook despite a range of dark clouds on the horizon. Since the last interview, a new President has been elected in arguably the most powerful nation on earth. The global direction of the political landscape is being rocked to the core. Perhaps Adriane, Taibanz and others stated correctly in their summation of the biggest problem is that "... people are selfish and do not think of the needs of others. They think only of themselves and their hopes and needs. That's the real problem."

\section{REFERENCES}

BAGNALL, N. F. (ed.). Youth Transition in a Globalised Marketplace. New York: Nova Science Publishers, Inc., 2005.

BAGNALL, N.F. Education and Belonging. New York: Nova Science, 2012.

BAGNALL, N.F. Global Identity in Multicultural and International Educational Contexts. Student identity formation in international schools. Routledge London and New York, 2015.

BECK, G. In: Lauder, H., BROWN, P., Dillabough, J., Halsey, A.H., (2006). Education, Globalization and Social Change. New York: Oxford University Press, 2002.

BUCX, F. Linked Lives. Young Adults' Life Course and Relations with Parents. Dissertation. Utrecht: Utrecht University, 2009.

CAIRNS, D. Youth transitions, international student mobility and spatial reflexivity. Being Mobile? United Kingdom: Palgrave Macmillan, 2014.

CHOPRA.; GAJJALA, R. (Eds). Global media, culture, and identity: Theory cases and approaches. New York, NY and London Routledge, 2011.

CRESWELL, J.W.; PLANO CLARKE, V. L.,. Designing and conducting mixed methods research. Thousand Oaks, CA: Sage, 2007.

CROZIER, M. On ne change pas la société par décret. Paris: Bernard Grasset, 1979. 


\section{RevistAleph}

DALY. M. Changing Family Life in Europe: Significance for State and Society. European Societies 7 (3), 379-398, 2005.

Freire, P. Pedagogy of the Oppressed. New York: Herder and Herder, 1970.

FREJKA , T.; SOBOTKA, T. Overview Chapter 1: Fertility in Europe. Diverse, Delayed and Below Replacement In: T.Frejka, J. Hoem, T. Sobotka, and L. Toulemon, Childbearing Trends and Policies in Europe An Overview, Demographic Research, Volume 19, Max Planck Demographic Institute, 15-46, 2008.

GALLAND, O. 'What Is Youth?' In: A. Cavalli and O. Galland (eds) Youth in Giampapa, F., \& Lamoureux, S. A. (2011). Voices from the field: Identity, language, and power in multilingual research settings. Journal of Language, Identity \& Education, 10(3), 127-131, 1995.

HANTRAIS , L. 'Living as a Family in Europe' In: L. Hantrais, D. Philipov, F.C. Billari, Policy Implications of Changing Family Formation, Population studies no.49. Council of Europe Publishing, pp.117 -181, 2006.

KAUFMANN, F.X. 'Politics and Policies towards the Family in Europe' in Knijin, T., (2012). Work family policies and transitions to adulthood in Europe. UK, USA: Palgrave Macmillan, 2002.

LANDIS, D., BENNETT, J.M., BENNETT, M.J., (Eds), Handbook of intercultural training. $\left(2^{\text {nd }}\right.$ ed., 163-188). Thousand Oaks, CA: Sage.

LEWIS , J. Work-Family Balance, Gender and Policy (Cheltenham, UK, and Northampton, Massachusetts, USA: Edward Elgar Publishing Ltd), 2009.

MARKAUSKAITE, L.; FREEBODY, P.; IRWIN, J. Methodological choice and design: Scholarship, policy and practice in social and educational research. New York, NY: Springer, 2011.

MILES, S. Youth Lifestyles in a changing world. Buckingham: Open University Press, 2000. MULLINGS, B. Insider or outsider, both or neither: some dilemmas of interviewing in a cross-cultural setting. Geoform, 30, 337-350. no.49. Council of Europe Publishing, 117181, 1999.

SARACENO, C. 'Introduction: Intergenerational Relations in Families: A Micro-macro Perspective' in C. Saraceno (ed.), Families, Ageing and Social Policy. Intergenerational Solidarity in European Welfare States (Cheltenham, UK, and Northampton, MA, USA: Edward Elgar Publishing Limited), 1-19, 2008a.

SCHMID, G. 'Social Risk Management through Transitional Labour Markets'. SocioEconomic Review 4, 1-33, 2006.

SOBOTKA, T.; L. TOULEMON. 'Overview Chapter 4: Changing Family Society'. European Societies 7 (3), 379-398, 2008.

VERTOVEC, S.; COHEN, R. Conceiving Cosmopolitanism: Theory, Context, and Practice. Oxford: Oxford University Press, 2002. 